\title{
Fluorescence of Chlorophyll $a$ for Discovering Inhibitors of Photosynthesis in Plant Extracts
}

\author{
Ana C. de Carvalho, Jéssica P. Salvador, Thais de M. Pereira, Pedro Henrique A. Ferreira, \\ João Carlos S. Lira, Thiago A. M. Veiga* \\ Departamento de Ciências Exatas e da Terra, Universidade Federal de São Paulo (UNIFESP), São Paulo, Brasil \\ Email: "tveiga@unifesp.br
}

Received 12 July 2016; accepted 14 August 2016; published 17 August 2016

Copyright (C) 2016 by authors and Scientific Research Publishing Inc.

This work is licensed under the Creative Commons Attribution International License (CC BY).

http://creativecommons.org/licenses/by/4.0/

(c) (i) Open Access

\begin{abstract}
Aims: Twelve crude extracts were prepared from different parts of Pluchea sagittalis, Cecropia palmata and Brachiaria brizantha, and their effect on the light reaction of photosynthesis. Study Design: Use of fluorescence of ChL $a$ (Chlorophyll $a$ ) to detect inhibitors of photosynthesis in plant extracts. Place and Duration of Study: Instituto de Ciências Ambientais, Químicas e Farmacêuticas, Departamento de Ciências Exatas e da Terra, Universidade Federal de São Paulo (UNIFESP), between July 2015 and January 2016. Methodology: The samples had their effect on the light reaction of photosynthesis studied by Chlorophyll $a(\mathrm{Chl} a)$ fluorescence transient by the use of chloroplasts isolated from spinach leaves. As negative controls we used the same amounts of DMSO that have been employed to solubilize the samples, and as positive control we have used $10 \mu \mathrm{M}$ of the commercial herbicide DCMU (Diuron). Results: The extracts inhibited the photosynthesis, and their inhibition sites were located in the range of electron flow from OEC complex and between $P_{680}$ to $Q_{A}$ of PS II, and inhibited the photosystem II (PS II) by inducing the appearance of the transient bands $K$ and $J$. Conclusion: Our results suggest an indicative that the photochemical apparatus probably is failing at the donor and acceptor sides of PSII, causing damage to electron transport during the photosynthesis phenomenon.
\end{abstract}

\section{Keywords}

Fluorescence of ChL $a$, Dereplication, Photosynthesis, Natural Products

\section{Introduction}

The world population is projected to grow to 9.7 billion in 2050 [1]. In this context, food, fibre and fuel de-

"Corresponding author.

How to cite this paper: de Carvalho, A.C., Salvador, J.P., Pereira, T. de M., Ferreira, P.H.A., Lira, J.C.S. and Veiga, T.A.M. (2016) Fluorescence of Chlorophyll $a$ for Discovering Inhibitors of Photosynthesis in Plant Extracts. American Journal of Plant Sciences, 7, 1545-1554. http://dx.doi.org/10.4236/ajps.2016.711146 
mands tend to increase, and the development of weeds management practices is the need on control of weeds and pests, responsible for reducing the yield of food crops. The weeds compete with food crops for nutrients, water and space, being able to drain significantly the quality of crops [2]. Although the pesticide industries developed a lot of synthetic herbicides to control weeds, exploring sundry of action mechanisms, the search is continuous for new herbicides more efficient, of wide spectrum, lower use rates and safe to crop and environment.

One of the strategies used to identify new chemical agents to control weeds is about the exploration of natural products either directly as herbicides [3] or as leads for the development of new commercial products. The most of compounds isolated from nature have not been evaluated for agrochemical purpose and for this reason this strategy is considered attractive.

The most natural products are water soluble while the majority of synthetic agrochemicals are not. Moreover, due to natural selection these compounds can present bioactivity in very low concentration. The great variety of chemical structures found in nature can afford chemical agents for weed control that are toxicologically and environmentally safe. The molecular sites of natural products can be quite different from known molecular targets and this fact is important for solving the resistance problem [4]. For instance, few natural products lead to commercial herbicides as mesotrione, sulcotrione, cinmethylin, bialaphos and gliphosinate. These pesticides act on molecular sites that were not known before they were introduced [5]-[8].

Furthermore, an increasing number of other natural products have been reported in the literature as models for the development of chemical agents for weed control as coumarins, benzoquinones, flavonoids, terpenoids and lactones [9]. The natural product research has been explored to develop new models for inhibitors of photosynthesis and the advances in this field are based on approaches like advancements in automation (high-throughput screening) and isolation technologies resulting in a development at the natural products area both in the fields of human health and agriculture [10].

The crucial step in the discovery of new chemical entities is the fast identification of substances in the real biological screening libraries: natural products, for instance, plants. Therefore, exploring plant's potential is a limited deal to experimental general manner of purification from crude extracts by time-consuming fractionation process, which also requires extensive chromatography. Dereplication approach permits early identification of known compounds without manual structure elucidation [11].

Dereplication is the process of differentiating those natural product extracts that contain nuisance compounds, or known specialized metabolites, from those that contain novel compounds that are of interest [11] and are identified comparing preliminary spectral data to spectral databases of known compounds. The most common approaches are LC-UV, LC-MS, LC-MS/MS, and LC-NMR, or combinations thereof. The dereplication based on LC-MS and LC-MS/MS is important because it is sensitive and provides structural information which is searchable in databases [12].

Moreover, combined with the powerful analytical strategies to obtain unknown chemical entities is extremely important the selection of a sensitive, fast and wide technique for elucidating the mechanisms of action of a new candidate to herbicide. According to Meyer \& Genty (1999) [13] the fluorescence of the chlorophyll $a$ (ChL $a$ ) allows easily to verify the photosynthetic electron transport activity in leaves, providing a detailed analysis of the photosynthesis inhibition, for example information about the PSII (photosystem II) state. This technique is important to detect the efficacy of the studied compounds as inhibitors of PSII.

It can suggests the extent to which PSII is using the energy absorbed by chlorophyll and the extent to which it is being damaged by excess light. The flow of electrons through PSII is indicative, under many conditions, of the overall rate of photosynthesis. It gives us the potential to estimate photosynthetic performance, under conditions in which other methods would fail, in a manner that is almost instantaneous. PSII is also accepted to be the most vulnerable part of the photosynthetic apparatus to light-induced damage. Damage to PSII will often be the first manifestation of stress in a leaf [14].

The mechanism of action of several natural products have been suggested by fluorescence of ChL $a$. Measurements confirmed the behavior of the diterpene trachyloban-19-oic acid isolated from Iostephane heterophylla as QA-QB (Quinone A-Quinone B) inhibitor [15]. The triterpenes epifriedelinol and canophyllol affect the in vivo photosynthesis efficiency of the chloroplasts in leaves of Lolium perenne and Physalis ixocarpa as a response to a process of detoxification [16]. Isolated from Maytenus imbricata, 3,4-Seco-friedelan-3-oic acid showed the formation of the K-band, acting as inhibitor at the donor side of PSII [17]. The flavonoids chrysin and 7-dimethylnarangenin purified from propolis also had their mechanisms of action confirmed by fluorescence studies. These results indicated that both inhibited the acceptor side of PS II, exactly like the commercial herbi- 
cide DCMU (3-(3,4-dichlorophenyl)-1,1-dimethylurea) [18]. On the other hands, pachypodol inhibited the water-splitting enzyme activity [19].

Several reports about the chemical profile of the plants studied in this work revealed, for example, the presence of monoterpenes, sesquiterpenes, triterpenes and flavonoids in Pluchea genus [20]. Twelve eudesmane sesquiterpenes were isolated from Pluchea sagittalis [21]. Flavonoids as 3',4',5,7-tetrahydroxy-3,6,8-trimethoxy flavone, 3',5,7-trihydroxy-3,4',6-trimethoxy flavone, and 3',4',5-trihydroxy-3,6,7-trimethoxy also were isolated and identified [22]. The analgesic and anti-inflammatory activity of Pluchea sagittalis leaves is attributed to the presence of terpenic substances: stigmasterol, $\beta$-amyrin, taraxasterol and pseudo-taraxasterol [23]. The most commonly described substances in Cecropia genus are terpenoids, steroids [24] [25] and phenolic compounds, such as proanthocyanidins and flavonoids [26] [27]. From the dichloromethane extract of Cecropia palmata leaves were isolated escoparone and ursolic acid [28], as well as pomolic acid, $\alpha$-amyrin, $\beta$-amyrin and derivatives of stigmasterol [29]. Plants of Brachiaria genus have presented inhibition effects on the growth of some plants species [30]. Moreover, the extracts from shoots of B. brizantha inhibited the seed germination of Stylosanthes species [31] and seedling growth of cress, lettuce, Phleum pratense and Lolium multiflorum [32]. Allelopathic substances were isolated from Brachiaria brizantha, (6R,9S)-3-oxo- $\alpha$-ionol, (6R,9R)-3-oxo- $\alpha$-ionol, 4-ketopinoresinol [32], friedelin and friedelanol [33].

Based on these contexts, we can suggest that the photosynthetic system is an excellent target for the discovery of new compounds since the photosynthesis inhibition is fatal for the invasive plant and therefore is the principal focus of the actual study guided by the analytical methods for a rapid purification of the specialized metabolites.

\section{Experimental Part}

\subsection{Extracts Preparation, Tested Material, Chloroplasts Isolation and Chlorophyll Determination}

Roots and leaves of Pluchea sagittalis, and leaves of Cecropia palmata and Brachiaria brizantha (Table 1) were harvested at Mina do Sossego/Canaã dos Carajás (Pará state, Brazil). The crude extracts were obtained from the plant material by automatic method using Dionex ASE 350 extractor in the following solvents in order of polarity, hexane $(500 \mathrm{~mL})$, ethyl acetate $(500 \mathrm{~mL})$ and methanol $(500 \mathrm{~mL})$. The solvents were eliminated under reduced pressure by using rotary evaporator R-300 (Büchi) to obtain twelve extracts (Table 1). Stock solutions for all extracts were prepared using a DMSO (dimethyl sulfoxide; the maximum concentration of solvent mixture in the media was less than $1 \%$ ).

Intact chloroplasts were isolated from spinach leaves (Spinacea oleracea L.) obtained from a local market as previously described [34] [35]. Chloroplasts were suspended in the following medium: $400 \mathrm{mM}$ sucrose, $5 \mathrm{mM}$

Table 1. Crude extracts obtained from Pluchea saggitalis, Cecropia palmata and Brachiaria brizantha.

\begin{tabular}{|c|c|c|c|c|}
\hline Plant specie (Family) & Plant part & Extraction solvent & Identification & Obtained material (g) \\
\hline \multirow{6}{*}{$\begin{array}{l}\text { Pluchea sagittalis (Lam.) } \\
\text { Cabrera (ASTERACEAE) }\end{array}$} & \multirow{3}{*}{ Roots (Rt) } & Hexane & P1Rt-Hex & 1.3 \\
\hline & & Ethyl acetate & P1Rt-EtA & 1.5 \\
\hline & & Methanol & P1Rt-Met & 7.5 \\
\hline & \multirow{3}{*}{ Leaves (Lv) } & Hexane & P1Lv-Hex & 4.4 \\
\hline & & Ethyl acetate & P1Lv-EtA & 7.2 \\
\hline & & Methanol & P1Lv-Met & 16.5 \\
\hline \multirow{3}{*}{$\begin{array}{l}\text { Cecropia palmata Willd. } \\
\text { (URTICACEAE) }\end{array}$} & \multirow{3}{*}{ Leaves (Lv) } & Hexane & P2Lv-Hex & 9.3 \\
\hline & & Ethyl acetate & P2Lv-EtA & 1.2 \\
\hline & & Methanol & P2Lv-Met & 12.2 \\
\hline \multirow{3}{*}{ Brachiaria brizantha (POACEAE) } & \multirow{3}{*}{ Leaves (Lv) } & Hexane & P3Lv-Hex & 4.6 \\
\hline & & Ethyl acetate & P3Lv-EtA & 2.9 \\
\hline & & Methanol & P3Lv-Met & 70.2 \\
\hline
\end{tabular}


$\mathrm{MgCl}_{2}, 10 \mathrm{mM} \mathrm{KCl}$, and buffered with $0.03 \mathrm{M} \mathrm{Na}^{+}$-tricine at $\mathrm{pH}$ 8.0. They were stored as a concentrated suspension in the dark for $1 \mathrm{~h}$ at $4^{\circ} \mathrm{C}$. Intact chloroplasts were efficiently lysed to yield free thylakoids prior to each experiment by incubating them in the following electron transport medium: $100 \mathrm{mM}$ sorbitol, $10 \mathrm{mM} \mathrm{KCl}, 5$ $\mathrm{mM} \mathrm{MgCl} 2,0.5 \mathrm{mM} \mathrm{KCN}$, and $30 \mathrm{mM}$ tricine ((N-tris[hydroxymethyl]methylglicine; N-[2-hydroxy-1,1-bis (hydroxymethyl)ethyl]glycine) buffer (pH 8 with the addition of $\mathrm{KOH}$ ). Chlorophyll concentration was measured spectrophotometrically as reported [36] [37].

\subsection{Chlorophyll $a$ Fluorescence Determination}

Chlorophyll $a$ fluorescence was measured with a Hansatech Fluorescence Handy PEA (plant efficiency analyzer) in 10 min dark-adapted chloroplasts $\left(20 \mu \mathrm{g} \cdot \mathrm{mL}^{-1}\right)$ at room temperature in the presence of $100 \mu \mathrm{g} \cdot \mathrm{mL}^{-1}$ of each extract [34] [38], using red light intensity (broad band $650 \mathrm{~nm}$ ) of $2800 \mu \mathrm{mol} \mathrm{m}{ }^{-2} \cdot \mathrm{s}^{-1}$, provided by an array of three light emitting diodes. The pulse duration was $2 \mathrm{~s}$. To monitor Chl $a$ fluorescence transients, aliquots of dark adapted thylakoids were placed by gravity on filter paper with a dot-blot apparatus (Bio-Rad, United States) to ensure a homogeneous and reproducible distribution of thylakoids on the surface, then the filter paper were dipped immediately in $3 \mathrm{~mL}$ of electron transport medium with the tested sample.

\section{Results and Discussion}

\section{Chlorophyll a fluorescence of PSII measurements}

To find the interaction sites of the extracts at PSII level, fluorescence of Chl $a$ was measured on freshly lysed spinach chloroplasts incubated for $5 \mathrm{~min}$ in the dark at room temperature. Control chloroplast contained the amount of DMSO used for each treatment, the treated chloroplasts contained $100 \mu \mathrm{g} \cdot \mathrm{mL}^{-1}$ of each crude sample (ten replicates); chloroplasts incubated with Tris $\left(0.8 \mathrm{~mol} \cdot \mathrm{L}^{-1}\right)$ and $10 \mu \mathrm{M}$ DCMU were used as positive controls. Chlorophyll $a$ induction curves of thylakoids control showed an OJIP sequence similar to that previously described for plants, green algae, and cyanobacteria [39], except for the phase IP that was in part suppressed due to the effect of MV (methylviologen) [34].

The chloroplasts were infiltrated with DCMU, and the control samples showed almost identical $\mathrm{F}_{\mathrm{M}}$ (fluorescence level when quinone $A\left[Q_{A}\right]$ is transiently fully reduced) levels (Table 2). However, the $F_{M}$ level of treated

Table 2. Effect of the extracts from $P$. sagittalis, $C$. palmata and B. brizantha at $100 \mu \mathrm{g} / \mathrm{mL}$ on fluorescence parameters of thylakoids previously incubated for $5 \mathrm{~min}$ in the dark with $10 \mu \mathrm{M}$ of DCMU and $0.8 \mathrm{~mol} \cdot \mathrm{L}^{-1} \mathrm{Tris}, \mathrm{pH} 8.0$.

\begin{tabular}{ccccc}
\hline Samples & $\mathrm{F}_{0}$ & $\mathrm{~F}_{\mathrm{m}}$ & $\mathrm{F}_{\mathrm{v}} / \mathrm{F}_{\mathrm{m}}$ & Area \\
\hline Control & $1374 \pm 69$ & $3605 \pm 180$ & $0.622 \pm 0.03$ & $229,646 \pm 1148$ \\
Tris $0.8 \mathrm{M}$ & $1245 \pm 63$ & $708 \pm 35$ & $0.412 \pm 0.02$ & 0 \\
DCMU $10 \mu \mathrm{M}$ & $1595 \pm 80$ & $3265 \pm 164$ & $0.440 \pm 0.02$ & $273,685 \pm 685$ \\
P1Rt-Hex & $1371 \pm 68$ & $3632 \pm 182$ & $0.632 \pm 0.03$ & $225,978 \pm 11,299$ \\
P1Rt-EtA & $1572 \pm 79$ & $3438 \pm 132$ & $0.543 \pm 0.02$ & $267,792 \pm 13,390$ \\
P1Rt-Met & $1257 \pm 63$ & $3118 \pm 156$ & $0.597 \pm 0.03$ & $156,537 \pm 7827$ \\
P1Lv-Hex & $1606 \pm 80$ & $3033 \pm 152$ & $0.470 \pm 0.02$ & $165,586 \pm 8280$ \\
P1Lv-EtA & $1195 \pm 60$ & $2771 \pm 139$ & $0.569 \pm 0.03$ & $122,153 \pm 6108$ \\
P1Lv-Met & $1523 \pm 80$ & $2253 \pm 123$ & $0.768 \pm 0.04$ & $160,185 \pm 8009$ \\
P2Lv-Hex & $1552 \pm 78$ & $2713 \pm 136$ & $0.797 \pm 0.04$ & $158,655 \pm 7933$ \\
P2Lv-EtA & $1468 \pm 73$ & $2404 \pm 120$ & $0.805 \pm 0.04$ & $113,150 \pm 5658$ \\
P2Lv-Met & $1421 \pm 71$ & $2034 \pm 102$ & $0.793 \pm 0.04$ & $148,776 \pm 7439$ \\
P3Lv-Hex & $1500 \pm 75$ & $2178 \pm 109$ & $0.770 \pm 0.04$ & $97,085 \pm 4854$ \\
P3Lv-EtA & $1475 \pm 74$ & $1889 \pm 95$ & $0.749 \pm 0.04$ & $52,909 \pm 2645$ \\
P3Lv-Met & $1505 \pm 75$ & $1189 \pm 60$ & $0.575 \pm 0.03$ & \\
\hline
\end{tabular}


chloroplasts decreased in comparison to the control, while the $\mathrm{F}_{0}$ (fluorescence level when plastoquinone electron acceptor pool $\left[\mathrm{Q}_{A}\right]$ is fully oxidized) was not affected by most of the evaluated extracts.

The fluorescence of chlorophyll $a$ transients (Table 3) were normalized, and the difference between the treated and control normalized transients revealed an increase in intensity between 2 and $4 \mathrm{~ms}$ appearing a $J$-band in the presence of the extracts from P. sagittalis (P1Rt-Hex, P1Rt-EtA, P1Rt-Met, P1Lv-Hex, P1Lv-EtA and P1Lv-Met). The $J$-band (Figure 1, panels A and B) provides information about single turnover events of the primary reactions of the photochemistry, mainly $\mathrm{Q}_{\mathrm{A}}$ reduction, suggesting that the electron transport beyond $\mathrm{Q}_{\mathrm{A}}$ is blocked at the $\mathrm{Q}_{\mathrm{B}}$ level as DCMU does, indicating these samples contain substances that interact at this site and the unused energy is dissipated as heat [35].

On the other hand, the addition of $0.8 \mathrm{~mol} \cdot \mathrm{L}^{-1}$ Tris, $\mathrm{pH}$ 8.0, a well-known donor site inhibitor of PSII [36], resulted in the formation of a $K$-band followed by a dip; the $K$ step arises when the electron flow to the acceptor side exceeds the electron flow from the donor side [37]. The $K$-band appears clearly and consists of a rapid rise to a maximum at $300 \mu$ s followed by a decrease to a level close to $\mathrm{F}_{0}$ (Figure 2(a)). The other steps, $J$ and $I$, are absent from the transient, as is shown by heat-treated samples [40], conditions in which the electron flow from $\mathrm{P}_{680}$ to $\mathrm{Q}_{\mathrm{A}}$ results in the formation of the K-band. The fast initial fluorescence rise is due to the reduction of $\mathrm{Q}_{\mathrm{A}}$ followed by the reduction of $\mathrm{P}_{680}^{+}$by $\mathrm{Z}$ without the direct participation of the OEC. The subsequent reduction in fluorescence yield apparently results from the opening of the reaction center by reoxidation of $\mathrm{Q}_{\mathrm{A}}$ and/or accumulation of $\mathrm{P}_{680}^{+}$, both of which are effective fluorescence quenchers [37]. Furthermore, the analysis of the Chl $a$ fluorescence transient in this work indicates that the water-splitting enzyme was blocked by the extracts P2Lv-Hex, P2Lv-EtA, P2Lv-Met, P3Lv-Hex, P3Lv-EtA and P3Lv-Met.

Table 3. Derived parameters, their description and formula using data extracted from the Chl $a$ fluorescence (OJIP) transients.

\begin{tabular}{|c|c|}
\hline \multicolumn{2}{|c|}{ Fluorescence parameters derived from the extracted data } \\
\hline $\mathrm{dV} / \mathrm{dto}=4\left(\mathrm{~F} 300 \mu \mathrm{s}-\mathrm{F}_{0}\right) /\left(\mathrm{F}_{\mathrm{M}}-\mathrm{F}_{0}\right)$ & Approximated initial slope (in $\mathrm{ms}^{-1}$ ) of the fluorescence transient $\mathrm{V}=\mathrm{f}(\mathrm{t})$ \\
\hline $\mathrm{Sm}=($ Area $) /\left(\mathrm{F}_{\mathrm{M}}-\mathrm{F}_{0}\right)$ & $\begin{array}{l}\text { Normalized total complementary area above } \\
\text { the OJIP transient (reflecting multiple turnover } \mathrm{Q}_{\mathrm{A}} \text { reduction events) }\end{array}$ \\
\hline \multicolumn{2}{|r|}{ Yields or flux ratios } \\
\hline $\mathrm{TRo} / \mathrm{ABS}=\left[1-\mathrm{F}_{0} / \mathrm{F}_{\mathrm{M}}\right]$ & Maximum quantum yield of primary photochemistry at $t=0$ \\
\hline$\varphi_{\mathrm{Eo}_{0}}=\mathrm{ETo} / \mathrm{ABS}=\left[1-\left(\mathrm{F}_{\mathrm{J}} / \mathrm{F}_{\mathrm{M}}\right)\right]$ & Quantum yield for electron transport at $\mathrm{t}=0$ \\
\hline$\psi_{o}=\mathrm{ETo} / \mathrm{TRo}=\left(1-\mathrm{V}_{\mathrm{J}}\right)$ & $\begin{array}{l}\text { Probability }(\text { at } t=0) \text { that a trapped exciton moves an electron } \\
\text { into the electron transport chain beyond } \mathrm{Q}_{\mathrm{A}}^{-}\end{array}$ \\
\hline \multicolumn{2}{|c|}{ Specific fluxes or activities per reaction center $(R C)$} \\
\hline $10 \mathrm{RC} / \mathrm{ABS}=\mathrm{Mo}(1 / \mathrm{VJ})\left(1 / \varphi_{\mathrm{P}_{\mathrm{O}}}\right)$ & Absorption per RC \\
\hline $\mathrm{TRo} / \mathrm{RC}=\mathrm{Mo} / \mathrm{V}_{\mathrm{J}}$ & Trapped energy flux per RC (at $\mathrm{t}=0$ ) \\
\hline $\mathrm{ETo} / \mathrm{RC}=\mathrm{Mo}\left(1 / \mathrm{V}_{\mathrm{J}}\right) \psi_{\mathrm{o}}$ & Electron transport flux per RC (at $\mathrm{t}=0$ ) \\
\hline \multicolumn{2}{|c|}{ Phenomenological fluxes or activities per excited cross section (CS) } \\
\hline $\mathrm{ABS} / \mathrm{CSo} \approx \mathrm{F}_{0}$ & Absorption flux per CS, approximated by $\mathrm{F}_{0}$ \\
\hline $\mathrm{TRo} / \mathrm{CS}=\varphi_{\mathrm{Po}}(\mathrm{ABS} / \mathrm{CSo})$ & Trapped energy flux per CS (at $\mathrm{t}=0$ ) \\
\hline $\mathrm{ETo} / \mathrm{CS}=\varphi_{\mathrm{Eo}}(\mathrm{ABS} / \mathrm{CSo})$ & Electron transport flux per CS (at $t=0$ ) \\
\hline \multicolumn{2}{|r|}{ De-excitation rate constants } \\
\hline$K p$ & Photochemical de-excitation rate constant \\
\hline Kn & Non-photochemical de-excitation rate constant \\
\hline $\operatorname{Sum} K$ & The sum of photochemical and non-photochemical rate constants \\
\hline \multicolumn{2}{|r|}{ Performance index } \\
\hline $\mathrm{PI}=\mathrm{RC} /(\mathrm{ABSRC}) \times \varphi_{\mathrm{P}_{0}} /\left(1-\varphi_{\mathrm{P}_{0}}\right) \times \psi_{o} /\left(1-\psi_{o}\right)$ & Performance index on absorption basis \\
\hline
\end{tabular}



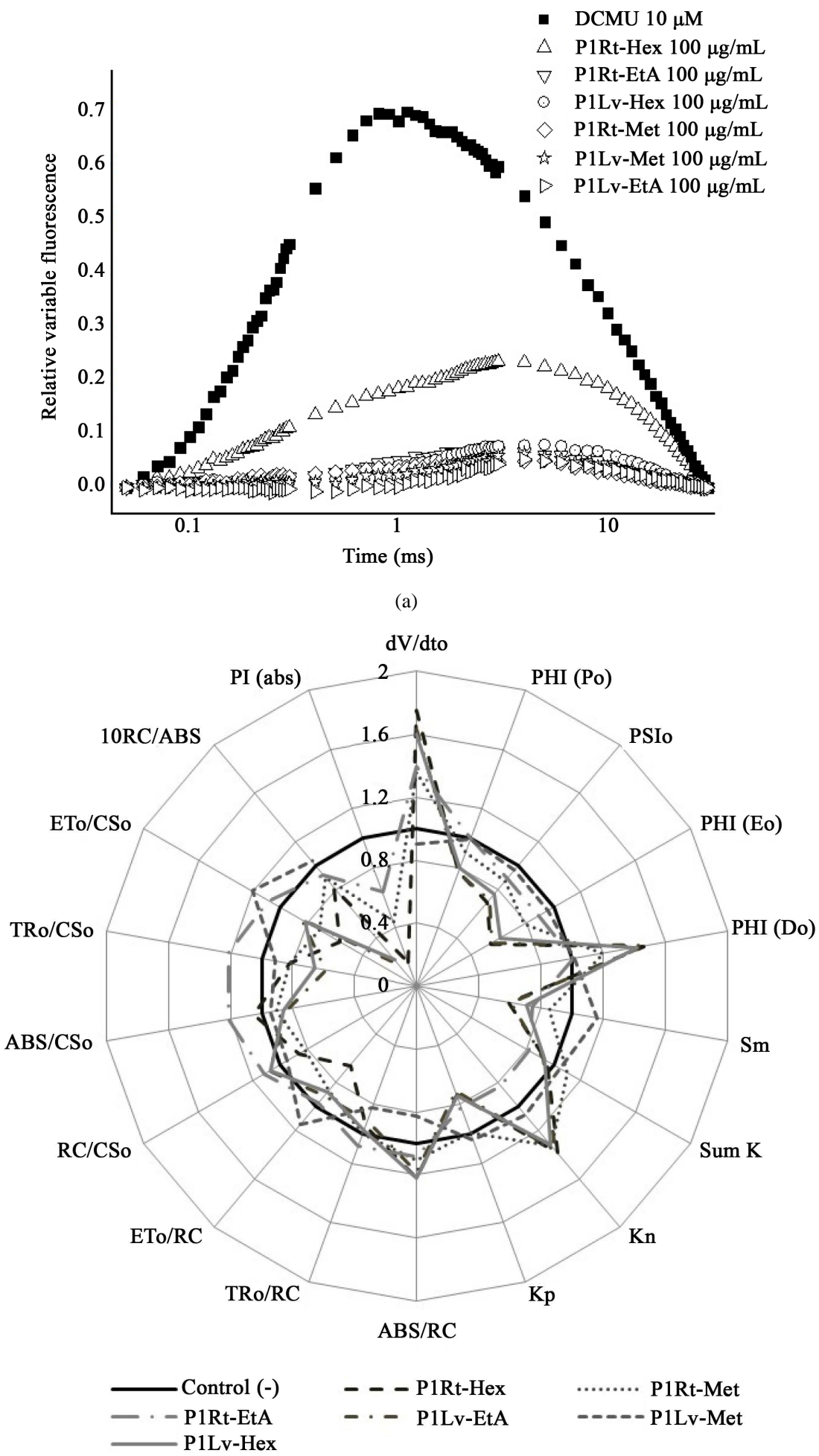

(b)

Figure 1. (a) Effect of extracts from $P$. sagittalis on different calculated parameters from OJIP curves measured in treated spinach chloroplasts. Appearance of the J-band at approximately $2000 \mu$ s in the presence of the samples at $100 \mu \mathrm{g} \cdot \mathrm{mL}^{-1}$. Data are an average of ten replicates; (b) Radar plot showing the JIP-test analysis for extracts from roots and leaves of Pluchea sagittalis. (Notes: J-band appears when the compound inhibits the electron transport at the acceptor side of the PSII) 


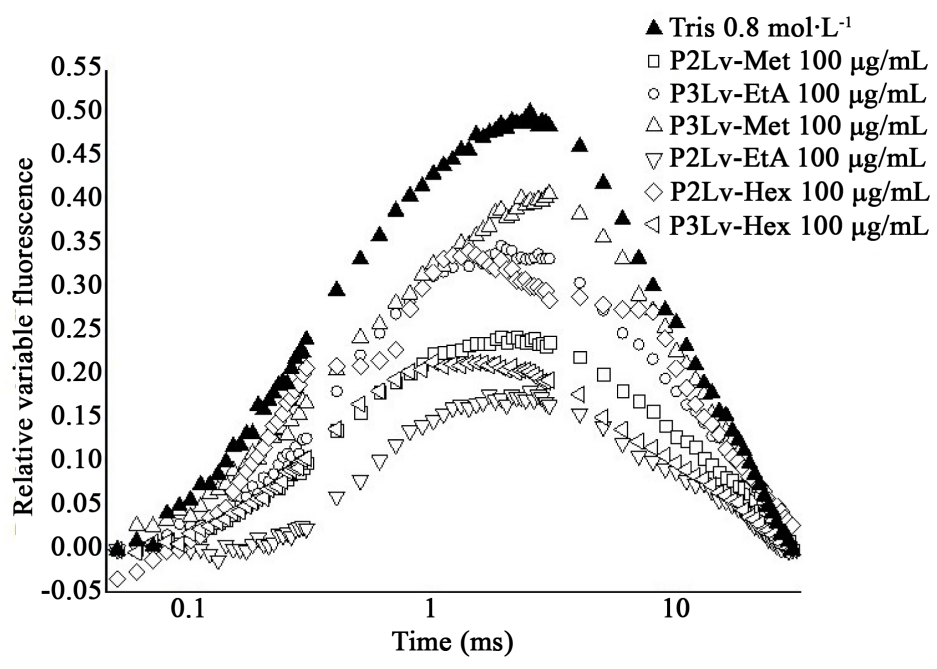

(a)

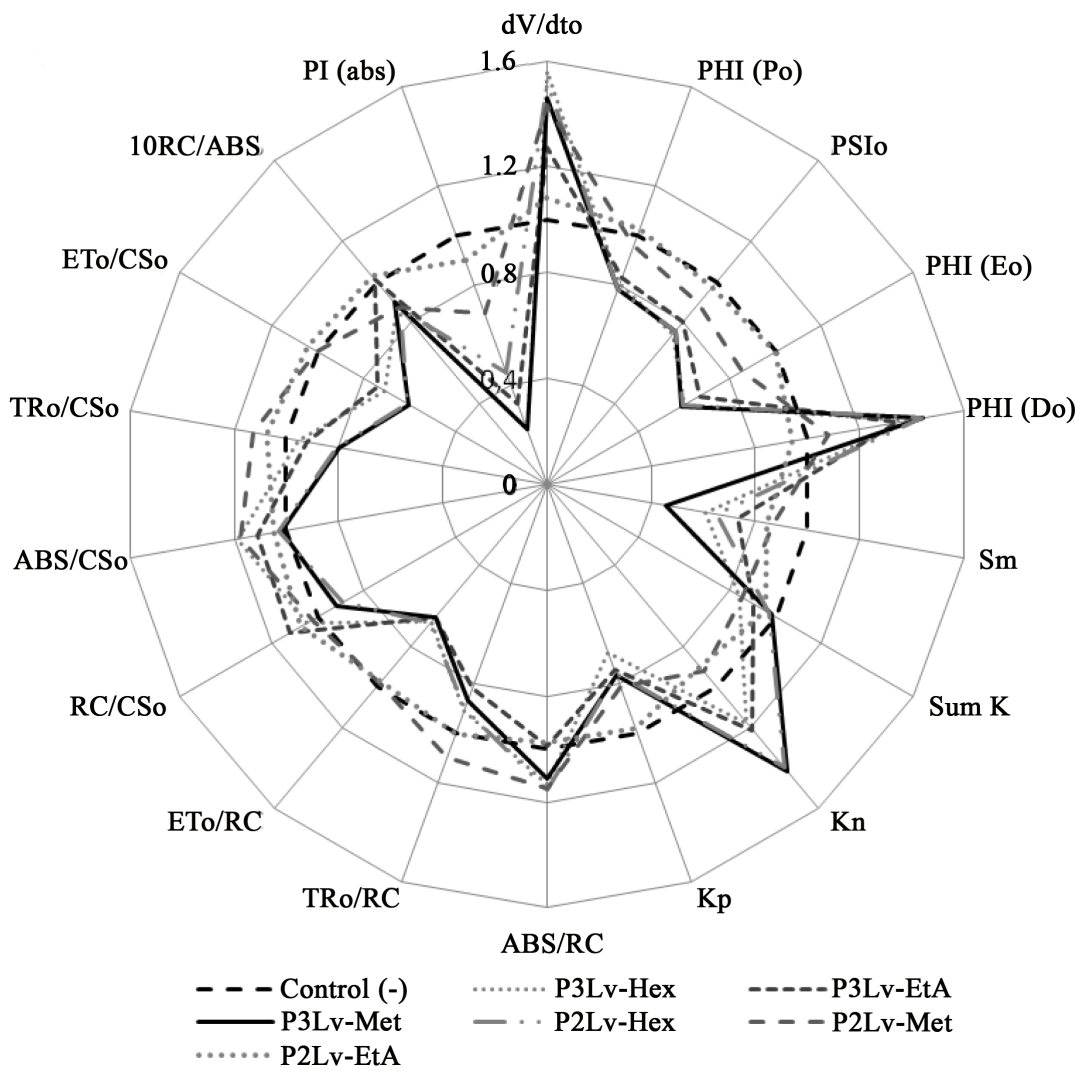

(b)

Figure 2. (a) Effect of extracts from C. palmata and B. brizantha on different calculated parameters from OJIP curves measured in treated spinach chloroplasts. Appearance of the K-band at approximately $300 \mu \mathrm{s}$ in the presence of the samples at 100 $\mu \mathrm{g} \cdot \mathrm{mL}^{-1}$. Data are an average of ten replicates; (b) Radar plot showing the JIP-test analysis for extracts from leaves of Cecropia palmata and Brachiaria brizantha. (Notes: K-band appears when the compound inhibits the electron transport at the donor side of the PSII; PI (abs), performance index; (ABS/RC), absorption per reaction center; PHI(Do), quantum yield for energy dissipation; $d V / d t o$, water splitting enzyme function; ETo/CSo, electron transport per cross section; PHI(Po), maximum quantum yield of primary photochemistry; PSI0, trapped exciton moves an electron into the electron transport chain beyond $\mathrm{Q}_{\mathrm{A}}{ }^{-}$; RC/CSo, density of the reaction centers; TRo/CSo and ETo/CSo, trapping and the electron transport per cross section) 
These observations have been confirmed by the analysis of Figure 2(b). Chlorophyll $a$ fluorescence is an intrinsic evidence of the photosynthetic system and the intensity of the fluorescence is a direct measure of the PS II activity. From the kinetics data of the fluorescence curve measured after treatment on chloroplasts and compared with the control, several parameters were calculated and plotted as a radar graph, a circular graphic with a series of spokes or rays projecting from a central point, with each ray label representing a different variable (Figure 2(b)). Data values were normalized to a common specific range or percentile values. The radar shows the parameters [35] affected by the evaluated extracts. When the extracts from B. brizantha (P3Lv-Hex, P3LvEtA and P3Lv-Met) have been evaluated at $100 \mu \mathrm{g} \cdot \mathrm{mL}^{-1}$, PI (abs), performance index, decreased from 10 to $80 \%$. The same parameter was less affected in the presence of the samples from C. palmata (P2Lv-Hex, P2LvEtA and P2Lv-Met) in a range between $10 \%$ to $50 \%$.

On the other hand, under the presence of B. brizantha extracts we observed an increase of some parameters: $10 \%$ - $20 \%$ of absorption per reaction center (ABS/RC); up to $50 \%$ of the quantum yield for energy dissipation PHI (Do), and the indicator of the water splitting enzyme function (dV/dto) were $40 \%-60 \%$ at $100 \mu \mathrm{g} \cdot \mathrm{mL}^{-1}$. Furthermore, the ethyl acetate and methanol extracts from this plant have caused a decrease of $25 \%$ on the electron transport per cross section (ETo/CSo) and the maximum quantum yield of primary photochemistry [PHI(Po)] decreased around 20\% (Figure 2(b)).

The probability that a trapped exciton moves an electron into the electron transport chain beyond $\mathrm{Q}_{\mathrm{A}}-$ (PSI0), the density of the reaction centers (RC/CSo), the trapping and the electron transport per cross section (TRo/CSo and ETo/CSo) decreased both of them around 10\% and 50\%. These observations suggested that some PSII RCs were transformed to "heat sinks" or "silent reaction centers"; these centers can neither reduce $\mathrm{Q}_{\mathrm{A}}$ and their excitation energy is dissipated as heat [35], this is the reason why PHI(Do) values increased in some cases up to $150 \%$, in the presence of the $B$. brizantha extracts.

In a similar behavior of some samples assayed here, many natural products also have presented a transient $J$-band (Figure 1(a)), like the alkaloids 1,3,5-trihydroxy-10-methyl-2,8-bis(3-methylbut-2-en-1-yl)-9(10H)acridinone, (2R)-2-tert-butyl-3,10-dihydro-4,9-dihydroxy-11-methoxy-10-methylfuro-[3,2-b]acridin-5(2H)-one, (3R)-2,3,4,7-tetrahydro-3,5,8-trihydroxy-6-methoxy-2,2,7-trimethyl-12H-pyrano[2,3-a]acridin-12-one [41] and evolitrine [35]. On the other hand, specialized metabolites like labdane-8a,15-diol [42] and citrusinine-I [41] indicated clearly the appearance of a K-band (Figure 2(a)).

\section{Conclusion}

Our data showed that the evaluated extracts have a great in vitro potential of inhibition on both sides of the photosystem II light reactions, once most of them have presented effect on photosynthesis under moderate concentrations $\left(100 \mu \mathrm{g} \cdot \mathrm{mL}^{-1}\right)$. Based on these results we can show to the scientific community how powerful and sensitive the fluorescence of ChL $a$ technique can be. Therefore, the main goal of our study is the use of dereplication of natural products approaches to isolate natural products from the active extracts to obtain models for herbicides, and then it is suggested that specialized metabolites from plants or microorganisms still can be employed on programs to discover good candidates of new lead molecules in the near future.

\section{Acknowledgements}

The authors acknowledge financial support from FAPESP (Fundação de Amparo à Pesquisa do Estado de São Paulo, Processes: 2010/51313-0; 2014/20339-5; 2013/21474-0; 2013/11273-8 and 2013/03663-0).

\section{References}

[1] UN DESA Report (2015) World Population Prospects: The 2015 Revision. http://www.un.org/en/development/desa/news/population/2015-report.html

[2] Teixeira, R.R., Pereira, J.L. and Pereira, W.L. (2012) Photosynthetic Inhibitors, Applied Photosynthesis. http://www.intechopen.com/books/applied-photosynthesis/photosynthetic-inhibitors

[3] Copping, L.G. and Duke, S.O. (2007) Natural Products That Have Been Used Commercially as Crop Protection Agents. Pest Management Science, 63, 524-554. http://dx.doi.org/10.1002/ps.1378

[4] Duke, S.O., Dayan, F.E., Kagan, I.A. and Baerson, S.R. (2005) New Herbicide Target Sites from Natural Compounds. ACS Simposium Series, 892, 151-160. http://dx.doi.org/10.1021/bk-2005-0892.ch014 
[5] Saxena, S. and Pandey, A.K. (2001) Microbial Metabolites as Eco-Friendly Agrochemicals for the Next Millennium. Applied Microbiology Biotechnology, 55, 395-403. http://dx.doi.org/10.1007/s002530000517

[6] Van K., J.W., Brophy, J.J., Perry, N.B. and Weavers, R.T. (1999) Triketones from Myrtaceae: Isoleptospermone from Leptospermum socparium and Papuanone from Corymbia dallachiana. Journal of Natural Products, 62, 487-489. http://dx.doi.org/10.1021/np980350n

[7] Mitchell, G., Barlett, D.W., Fraser, T.E.M., Hawkes, T.R., Holt, D.C., Townson, J.K. and Wichert, R.A. (2001) Mesotrione: A New Selective Herbicide for Use in Maize. Pest Management Science, 57, 120-128. http://dx.doi.org/10.1002/1526-4998(200102)57:2<120::AID-PS254>3.0.CO;2-E

[8] Chaabane, H., Cooper, J.F., Azouzi, L. and Coste, C.M. (2005). Influence of Soil Properties on the Adsorption-Desorption of Sulcotrione and Its Hydrolysis Metabolites on Various Soils. Journal of Agricultural and Food Chemistry, 53, 4091-4095. http://dx.doi.org/10.1021/jf040443c

[9] Barbosa, L.C.A., Teixeira, R.R. and Montanari, R.M. (2008) Phytotoxic Natural Products as Models for the Development of Crop Protection Agents. In: Epifano, F., Ed., Current Trends in Phytochemistry, 21-59.

[10] David, B., Wolfender, J.L. and Dias, D.A. (2015) The Pharmaceutical Industry and Natural Products: Historical Status and New Trends. Phytochemistry Reviews, 14, 299-315. http://dx.doi.org/10.1007/s11101-014-9367-z

[11] Lang, G., Mayhudin, N.A., Mitova, M.I., Sun, L., Van der Sar, S., Blunt, J.W., Cole, A.L., Ellis, G., Laatsch, H. and Munro, M.H. (2008) Evolving Trends in the Dereplication of Natural Product Extracts: New Methodology for Rapid, Small-Scale Investigation of Natural Product Extracts. Journal of. Natural Products, 71, 1595-1599. http://dx.doi.org/10.1021/np8002222

[12] Mohamed, A., Nguyen, C.H. and Mamitsuka, H. (2016) Current Status and Prospects of Computational Resources for Natural Product Dereplication: A Review. Briefings in Bioinformatics, 17, 309-321. http://dx.doi.org/10.1093/bib/bbv042

[13] Meyer, S. and Genty, B. (1999) Heterogenous Inhibition of Photosynthesis over the Leaf Surface of Rosa rubiginosa L. during Water Stress and Abscisic Acid Treatment: Induction of a Metabolic Component by Limitation of $\mathrm{CO}_{2}$ Diffusion. Planta, 210, 126-131. http://dx.doi.org/10.1007/s004250050661

[14] Maxwell, K. and Johnson, G.N. (2000) Chlorophyll Fluorescence-A Pratical Guide. Journal of Experimental Botany, 51, 659-668.

[15] Hernández-Terrones, M.G., Aguilar, M.I., King-Díaz, B. and Lotina-Hennsen, B. (2003) Inhibition of Photosystem II in Spinach Chloroplasts by Trachyloban-19-Oic Acid. Pesticide Biochemistry and Physiology, 77, 12-17. http://dx.doi.org/10.1016/S0048-3575(03)00066-X

[16] Torres-Romero, D., King-Díaz, B., Strasser, R.J., Jiménez, I.A., Lotina-Hennsen, B. and Bazzocchi, I.L. (2010) Friedelane Triterpenes from Celastrus vulcanicola as Photosynthetic Inhibitors. Journal of Agricultural and Food Chemistry, 58, 10847-10854. http://dx.doi.org/10.1021/jf1022115

[17] Ribeiro de Souza e Silva, S., Silva, G.D.F., Barbosa, L.L.A., Duarte, L.P., King-Díaz, B., Archundia-Camacho, F. and Lotina-Hennsen, B. (2007) Uncoupling and Inhibition Properties of 3,4-Seco-Friedelan-3-Oic Acid Isolated from Maytenus imbricata. Pesticide Biochemistry and Physiology, 87, 109-114. http://dx.doi.org/10.1016/j.pestbp.2006.06.008

[18] Varejão, J.O.S., Barbosa, L.C.A., Ramos, G.A., Varejão, E.V.V. and King-Díaz, B. (2015) New Rubrolide Analogues as Inhibitors of Photosynthesis Light Reactions. Journal of Photochemistry and Photobiology B: Biology, 145, 11-18. http://dx.doi.org/10.1016/j.jphotobiol.2015.02.016

[19] González-Vázquez, R., Díaz, B.K., Aguilar, M.I., Nelly, D. and Blas, L.H. (2006) Pachypodol from Croton ciliatoglanduliferus Ort. as Water-Splitting Enzyme Inhibitor on Thylakoids. Journal of Agricultural and Food Chemistry, 54, 1217-1221. http://dx.doi.org/10.1021/jf051897s

[20] Hussain, H., Al-Harrasi, A., Abbas, G., Rehman, N.U., Mabood, F., Ahmed, I., Saleem, M., Van Ree, T., Green, I.R., Anwar, S., Badshah, A., Shah, A. and Ali, I. (2013) The Genus Pluchea: Phytochemistry, Traditional Uses, and Biological Activities. Chemistry and Biodiversity, 10, 1944-1971. http://dx.doi.org/10.1002/cbdv.201200140

[21] Vera, N., Misico, R., Sierra, M.G. and Asakawa, Y. (2008) Eudesmanes from Pluchea sagittalis. Their Antifeedant Activity on Spodoptera frugiperda. Phytochemistry, 69, 1689-1694.

http://dx.doi.org/10.1016/j.phytochem.2008.02.020

[22] Martino, V.S., Ferraro, G.E., Debenedetti, S.L. and Coussio, J.D. (1984) Compuestos Polifenólicos aislados de Pluchea sagittalis (Compuestas). Acta Farmacéutica Bonaerense, 3, 141-146.

[23] Burger, M.E., Teixeira, E.P. and Scares, J. (2000) Action of the Extracts of Pluchea sagittalis on the Absorptive Characteristics of the Gastrointestinal Tract. Brazilian Archives of Biology and Technology, 43, 95-99. http://dx.doi.org/10.1590/S1516-89132000000100012 
[24] Hikawczuk, V.J., Saad, J.R., Guardia, T., Juarez, A.O. and Giordano, O.S. (1998) Anti-Inflammatory Activity of Compounds Isolated from Cecropia pachystachya. Anales de la Asociación Química Argentina, 86, 167-170.

[25] Rocha, G.G., Simões, M., Lúcio, K.A., Oliveira, R.R., Kaplan, M.A.C. and Gattass, C.R. (2007) Natural Triterpenoids from Cecropia lyratiloba Are Cytotoxic to Both Sensitive and Multidrug Resistant Leukemia Cell Lines. Bioorganic \& Medicinal Chemistry, 15, 7355-7360. http://dx.doi.org/10.1016/j.bmc.2007.07.020

[26] Lacaille-Dubois, M.A., Franck, U. and Wagner, H. (2001) Search for Potential Angiotensin Converting Enzyme (ACE)-Inhibitors from Plants. Phytomedicine, 8, 47-52. http://dx.doi.org/10.1078/0944-7113-00003

[27] Tanae, M.M., Lima-Landman, M.T.R., De Lima, T.C.M., Souccar, C. and Lapa, A.J. (2007) Chemical Standardization of the Aqueous Extract of Cecropia glaziovii Sneth Endowed with Antihypertensive, Bronchodilator, Antacid Secretion and Antidepressant-Like Activities. Phytomedicine, 14, 309-313. http://dx.doi.org/10.1016/j.phymed.2007.03.002

[28] Pinheiro, G.B.V., Arruda, M.S.P., Rebelo, A.C.R., Arruda, A.C. and Müller, A.H. (1998) Constituintes químicos das folhas de Cecropia palmata. Simpósio de Plantas Medicinais do Brasil, Águas de Lindóia, Programa e resumos, São Paulo, 98.

[29] Costa, G.M., Schenkel, E.P. and Reginatto F.H. (2011) Chemical and Pharmacological Aspects of the Genus Cecropia. Natural Product Communications, 6, 913-920.

[30] Martins, D., Martins, C.C. and Costa, N.V. (2006) Allelopathic Potential of Solutions of Soils Cultivated with Brachiaria brizantha: Effects on Some Pasture Grass and Weeds Seeds. Planta Daninha, 24, 61-70. http://dx.doi.org/10.1590/S0100-83582006000100008

[31] Rodrigues, A.P.D.C., Laura, V.A., Pereira, S.R. and Deiss, C. (2012) Allelopathy of Two Brachiaria Species in Seeds of Three Species of Stylosanthes. Ciencia Rural, 42, 1758-1763. http://dx.doi.org/10.1590/S0103-84782012001000007

[32] Kato-Noguchi, H., Kobayashi, A., Ohno, O., Kimura, F., Fujii, Y. and Suenaga, K. (2014) Phy-Totoxic Substances with Allelopathic Activity May Be Central to the Strong Invasive Potential of Brachiaria brizantha. Journal of Plant Physiology, 171, 525-530. http://dx.doi.org/10.1016/j.jplph.2013.11.010

[33] Santos, L.S., Santos, J.C.L., Souza Filho, A.P.S., Corrêa, M.J.C., Veiga, T.A.M., Freitas, V.C.M., Ferreira, I.C.S., Gonçalvea, N.S., Silva, C.E. and Guilhon, G.M.S.P. (2008) Atividade alelopática de substâncias químicas isoladas do capim-marandu e suas variações em função do pH. Planta Daninha, 26, 531-538. http://dx.doi.org/10.1590/S0100-83582008000300008

[34] Roux, D., Martin, M.T., Adeline, M.T., Sevenet, T., Hadi, H. and Pais, M. (1998) Foveolins A and B, Dammarane Triterpenes from Aglaia foveolata. Phytochemistry, 49, 1745-1748. http://dx.doi.org/10.1016/S0031-9422(98)00305-7

[35] Veiga, T.A.M., King-Díaz, B., Marques, A.S.F., Sampaio, O.M., Vieira, P.C., da Silva, M.F.G.F. and Lotina-Hennsen, B. (2013) Furoquinoline Alkaloids Isolated from Balfourodendron riedelianum as Photosynthetic Inhibitors in Spinach Chloroplasts. Journal of Photochemistry and Photobiology B, 120, 36-43. http://dx.doi.org/10.1016/j.jphotobiol.2013.01.006

[36] Morales-Flores, F., Aguilar, M.I., King-Díaz, B. and Lotina-Hennsen, B. (2013) Derivatives of Diterpen Labdane-8 $\alpha$, 15-Diol as Photosynthetic Inhibitors in Spinach Chloroplasts and Growth Plant Inhibitors. Journal of Photochemistry and Photobiology B, 125, 42-50. http://dx.doi.org/10.1016/j.jphotobiol.2013.04.010

[37] Mills, J.D., Mitchell, P. and Schurmann, P. (1980) Modulation of Coupling ATPase Activity in Intact Chloroplasts. FEBS Letters, 191, 144-148.

[38] Strasser, R.J. and Govindjee, S.A. (1995) Polyphasic Chlorophyll $\alpha$ Fluorescence Transient in Plants and Cyanobacteria. Photochemistry and Photobiology, 66, 32-36. http://dx.doi.org/10.1111/j.1751-1097.1995.tb09240.x

[39] Mohamad, K., Sevenet, T., Dumontet, V., Pais, M., Tri, M.V., Hadi, H., Awang, K. and Martin, M. (1999) Dammarane Triterpenes and Pregnane Steroids from Aglaia lawii and A. tomentosa. Phytochemistry, 51, 1031-1037. http://dx.doi.org/10.1016/S0031-9422(99)00053-9

[40] Strain, H.H., Cope, T. and Svec, M.A. (1971) Analytical Procedures for the Isolation, Identification, Estiation and Investigation of the Chlorophylls. Methods Enzymology, 23, 452-466. http://dx.doi.org/10.1016/S0076-6879(71)23118-9

[41] Arato-Ferreira, P.H., Dos Santos, D.A.P., Da Silva, M.S.G.F., Vieira, P.C., King-Diaz, B., Lotina-Hennsen, B. and Veiga, T.A.M. (2016) Acridone Alkaloids from Swinglea glutinosa (Rutaceae) and Their Effects on Photosynthesis. Chemistry \& Biodiversity, 13, 100-106. http://dx.doi.org/10.1002/cbdv.201500046

[42] Morales-Flores, F., Aguilar, M.I., King-Diaz, B. and De Santiago-Gomez, J.R. (2007) Natural Diterpenes from Croton ciliatoglanduliferus as Photosystem II and Photosystem I Inhibitors in Spinach Chloroplasts. Photosynthesis Research, 91, 71-80. http://dx.doi.org/10.1007/s11120-007-9143-7 


\section{Submit or recommend next manuscript to SCIRP and we will provide best service for you:}

Accepting pre-submission inquiries through Email, Facebook, LinkedIn, Twitter, etc.

A wide selection of journals (inclusive of 9 subjects, more than 200 journals)

Providing 24-hour high-quality service

User-friendly online submission system

Fair and swift peer-review system

Efficient typesetting and proofreading procedure

Display of the result of downloads and visits, as well as the number of cited articles

Maximum dissemination of your research work

Submit your manuscript at: http://papersubmission.scirp.org/ 